\title{
Chinese Exchange Rate and G3 Import Prices: A Coalition Game
}

\author{
Ning Zeng* \\ International Business School, Jinan University, Guangdong 519070, China
}

\begin{abstract}
This paper explores the multilateral trading strategies between China and G3 through a coalition game. By investigating the role of China's exchange rate regime among multilateral tradings, findings highlight that China's multilateral trading strategy with G3 is beneficial for each participating member. Moreover, if China follows an assignment game, then the multilateral trading is balanced. Anlyses in this paper also suggest that China's exchange rate policy does play a major role for balancing the tradings between China and G3. Future work may test the empirical data for practical results.
\end{abstract}

Keywords: Exchange rate; Coalition game; Multilateral tradings.

\section{Introduction}

As one of fastest growing countries, China has been playing an important role in the world. In recent years, China's exchange rate policy has been the topic of intense debate in which much of the literature is supportive of the view that China should move to a more flexible exchange rate regime. Though Chinese authority declares that its exchange rate regime is a managed float, the International Monetary Fund (IMF) has registered China's exchange rate as a fixed peg to the US dollar since 1999. Also the renminbi (RMB) is observed to be undervalued (Frankel, 2005; Goldstein, 2003; Kujawa, 2005; Preeg, 2003), which is coincided with US politicians call to revalue the $\mathrm{RMB}$ in the belief that this would correct the US-China trade deficit and job losses (Frankel, 2006: 248). This paper examines the transmission channels between China and the US, the Euro zone and Japan (G3), in order to test whether a change in the Chinese exchange rate regime will be beneficial for trading between China and the G3.

This paper sets China and G3 as a coalition game, focuses on the transmission of exchange rate shocks via considering shocks in China's bilateral exchange rates with G3, and therefore tests the validity of the change of exchange rate regime. Findings show that the price effect dominates relative to the exchange rate effect, and thus concludes that China's exchange rate policy does play a major role for the balance of the trading between China and G3. And the change of China's exchange rate regime is beneficial for multilateral trade.

\section{Exchange rate and import prices}

A decline of a currency would be expected to boost prices of imported goods, used in the production of domestic prod-

\footnotetext{
*E-mail: tningzeng@jnu.edu.cn. I would like to acknowledge 'Jinan University Fund for Young Scholars' for financial support.
} 
ucts and services directly as well as indirectly. Hooper et al. (2000) estimate and test the stability of income and price elasticities derived from conventional equations relating the foreign trade of the Group of Seven (G7) countries to their incomes and relative prices. They find that a $1 \%$ drop in the dollar reduces US demand for imports by only $0.3 \%$ in the long term (Japan: -0.3\%; Germany: $0.06 \%$; France: $-0.4 \%$; Italy: $-0.4 \%$ ) While a $1 \%$ drop in income reduces imports by $1.8 \%$ (Japan: 0.9\%; Germany: 1.5\%; France: $1.6 \%$; Italy: $1.4 \%){ }^{2}$

Empirical evidence suggests that the exchange rate is not significant in determining import demand. So, may import costs be a crucial factor? China's price level has been experiencing ups and downs since 1980s. Figure 1 illustrates China's annual average CPI inflation declining from its peak of $24.1 \%$ in 1994 to near zero in 2003, peaking at $8.7 \%$ in February 2008, and slowing down to 3.6\% September 2010. As Cargill and Parker (2004) argued that deflation in China was largely supply-led, not demand-led like Japan, implying that structural factors may be playing a greater role currently than monetary variables, thereby China's cost of production is likely to stay low.

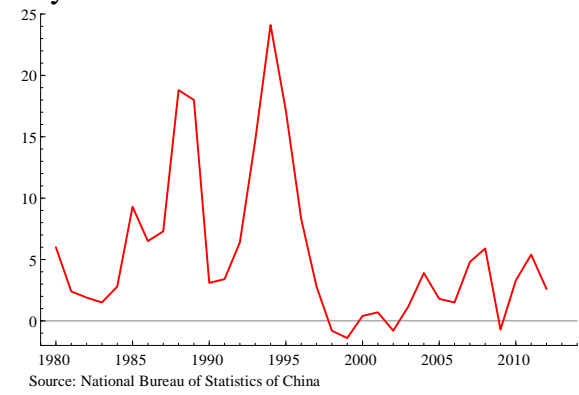

Fig. 1: China's inflation rates in 1980-2012

The key question is to what extent the movements in the exchange rate and in Chinese firms' production costs are reflected in changes in G3 import prices.

\footnotetext{
${ }^{2}$ See also Xu (2000).
}

Here, price proxies are used for production costs, which is a common practice in the literature. Let the G3 import prices $\left(P^{n g 3}\right)$ are a transformation of Chinese export prices $\left(P^{x c}\right)$ and the exchange rate $\left(E^{n}\right)$ is defined in terms of the Chinese currency (exporting country) per unit of the G3 currency (importing countries), assuming the law of one price for Chinese exports (LOOP) :

$$
P_{t}^{m g 3}=P_{t}^{x c} E_{t}^{n}
$$

As in eq. (2), the degree of changes in exchange rate changes are reflected in the prices of destination currency of traded goods is called exchange rate passthrough. If exporters price discriminate by adjusting their own prices to absorb the exchange rate shock, then the exchange rate changes will not be transmitted to buyer currency prices.

$$
\Delta \ln P_{t}^{m g 3}=\alpha+\phi_{\pi} \Delta \ln P_{t}^{x c}+\phi_{e x} \Delta \ln E_{t}^{n}
$$

Granville et al. (2011) employed a VAR-Vector Exponential Generalized Autoregressive Conditional Heteroscedasticity (VEGARCH) approach to investigate Chinese exchange rate and price effects on G3 import prices. Their findings suggest that reduced import prices from China appear to be the channel through which aggregate domestic prices in the G3 remain depressed. Also the RMB exchange rate policy matters little suggesting that a revaluation of the RMB will not do much to reduce the US trade deficit, as the price effect in China appears to be dominating the exchange rate effect. However, it should not be neglected that a relatively flexible RMB exchange rate against the Euro did make the EU exchange rate volatility more significant than the US dollar for China's export price volatility.

\section{A coalition game}

Here, a coalition game of China's mutilateral trade can be described as follows: 
Player 1 (China, seller) has products, which are worthless, i.e. non-profitable, unless are exported. Player 2, 3 and 4 (US, Euro zone and Japan, buyers) value the products at $p^{U S}, p^{E U}$ and $p^{J A}$, where $p^{U S}>$ $p^{E U}>p^{J A}$, based on exchange rates and China's price level respectively. So, which exchange regime, that is a fixed peg to the US dollar and a peg to basket of currencies, could be beneficial for China as well as G3?

This coalition of China and G3 is a collective decision-maker, and players are form the coalitions. The coalition worth of each coalition is the total amount that the players from the coalition can jointly guarantee themselves, which is measured in abstract units of utility.

Let $N=\{1,2,3,4\}$ be a finite set of players. A coalition is any subset of $N$. If China sells its products to the US at price $x$, China will effectively make a profit of $x$, while the profit of the US is $p^{U S}-x$. Therefore the total profit of the coalition $\{1,2\}$, denoted as $v(\{1,2\})$, is thus $p^{U S}$. Similarly, the total profit of $v(\{1,3\})$ and $v(\{1,4\})$ is $p^{E U}$ and $p^{J A}$ respectively. The grand coalition $N$ should assign the products to the US who can eventually give side payments to Euro zone and Japan. In terms of mathematics, the above is expressed as the following:

$v(\{1,2\})=v(N)=p^{U S}, v(\{1,3\})=p^{E U}$, $v(\{1,4\})=p^{J A}, v(\{i\})=v(\{2,3\})=v(\{2$, $4\})=v(\{3,4\})=0, i=1,2,3,4$.

The game $v$ is monotone, superadditive, but not convex:

$v(N)+v(\{1\})<v(\{1,2\})+v(\{1,3\})+v(\{1,4\})$.

A payoff vector in a game $v$ with a set of players $N=\{1, \ldots, \mathrm{n}\}$ is any vector $x=$ $\left(x_{1}, \ldots, x_{\mathrm{n}}\right) \in \mathrm{R}^{\mathrm{n}}$. Let $x(A)=\sum_{i \in A} x_{i}$, for every payoff vector $x$ and $A \subseteq N$.

A set $X_{v}=\{x \in \mathrm{R} \mid x(N) \leq v(N)\}$ is the set of feasible payoff vectors in a game $v$. Let $\Gamma$ be a set of games with a player set $N$. A solution is a function $\sigma$ that associ- ates with each game $v \in \Gamma$ a set $\sigma(v) \subseteq$ $\mathrm{X}_{v}$.

Let $\sigma$ be a solution on $\Gamma$ and $\sigma$ preserves

(i) nonempty on $\Gamma$ if $\sigma(v) \neq \varnothing$;

(ii) individual rationality if $x_{i} \geq v(\{i\})$ for every $i \in N$;

(iii) coalitional rationality if $x(A) \geq v(A)$ for every $A \subseteq N$;

(iv) treating players equally if the following condition is satisfied:

$$
v(A \cup\{i\})=v(A \cup\{j\}) \Rightarrow x_{i}=x_{j} \text {, for }
$$
each $\mathrm{A} \subseteq \mathrm{N}$

And the above properties must be satisfied for each $v \in \Gamma, \mathrm{x} \in \sigma(v)$.

Next, the core of the game (Shapley, 1953), is defined as: let $\Gamma$ be the set of all games with the player set $N=\{1, \ldots, \mathrm{n}\}$. For any $v \in \Gamma$, put $\mathrm{C}(v)=\left\{x \in \mathrm{R}^{\mathrm{n}} \mid x(N)\right.$ $=v(N), x(A) \geq v(A)$, for every $A \subseteq N\}$.

So a payoff vector $x \in \mathrm{R}^{\mathrm{n}}$ belongs to the core if and only if no coalition can improve upon $x$. And members of core are thus highly stable payoff vectors. Accordingly the core solution preserves individual and coalitional rationality. However the core solution need not be nonempty, treating players equally. And the core of this game is written as:

(i) $N=\{1,2,3,4\}$

(ii) $v(\{1,2\})=v(N)=p^{U S}$

$$
\begin{aligned}
& v(\{1,3\})=p^{E U}, v(\{1,4\})=p^{J A} \\
& v(\{i\})=v(\{2,3\})=v(\{2,4\}) \\
& \quad=v(\{3,4\})=0, i=1,2,3,4
\end{aligned}
$$

(iii) $\mathrm{C}(v)=\left\{\left(t, 0, p^{U S}-t\right) \in \mathrm{R}^{4} \mid p^{J A} \leq t \leq p^{U S}\right\}$

Each payoff vector $x \in \mathrm{C}(v)$ must satisfy:

$x_{i} \geq 0, i=1,2,3,4$

$\mathrm{x}_{1}+\mathrm{x}_{2} \geq p^{U S}$

$\mathrm{x}_{1}+\mathrm{x}_{3} \geq p^{E U}$

$\mathrm{x}_{1}+\mathrm{x}_{4} \geq p^{J A}$

$\mathrm{x}_{1}+\mathrm{x}_{2}+\mathrm{x}_{3}+\mathrm{x}_{4}=p^{U S}$

Therefore US will purchase the products at a price at least $p^{J A}$, Euro zone and Japan are priced out of the market after bidding up the price to $p^{J A}$.

Moreover, it is sensible to define an assignment game to solve China's multilat- 
eral trading strategy. As Shapley and Shubik (1971) explained, an assignment game is a model for a two-sided market with large products, which are exchanged for money, and each player either supplies or demands exactly one unit.

Let $N=S \cup B, \mathrm{~S}, \mathrm{~B} \neq \varnothing$ and $\mathrm{S} \cap \mathrm{B}=\varnothing$, and each $i \in S$ is a seller who has products of worth $\alpha_{i}$, each $j \in B$ is a potential buyer whose reservation price for $i$ 's products is $\beta_{i j}$. Define the joint net profit of $\{i, j\}$ as $w\{i, j\}=\max \left\{\beta_{i j}-\alpha_{i}, 0\right\}$. And then an assignment for $A \subseteq N$ is a set $\tau \subseteq 2^{A}$, such that for every $P, Q \in \mathcal{T}$ with $P \neq Q$. It is hereby indicated as follows:

$P \cap Q=\varnothing$ and $|P \cap S|=|P \cap B|=1$

The assignment game $v$ with respect to $\left(\alpha_{i}\right)_{i} \in \mathrm{S}$ and $\left(\beta_{i j}\right)_{\mathrm{i} \in \mathrm{S}, j \in \mathrm{B}}$ is here defined by $v(A)=\max \left\{\sum_{P \in \mathcal{T}} w(P) \mid \mathcal{T}\right.$ is an assignment for $A\}, A \subseteq N$.

So that, the assignment game of China and $\mathrm{G} 3$ is written as:

$N=\{1,2,3,4\}, S=\{1\}, B=\{2,3,4\}$

$w(\{1,2\})=p^{U S}, w(\{1,3\})=p^{E U}$,

$w(\{1,4\})=p^{J A}$. And assignments for $N$ are $\mathcal{T}_{1}=\{\{1,2\}\}, \mathcal{T}_{2}=\{\{1,3\}\}$ and $\mathcal{T}_{2}=$ $\{\{1,4\}\}$.

According to the theorem, every assignment game is balanced.

\section{Conclusions}

This paper analyses the multilateral trading strategies between China and G3 through a coalition game.

As earlier results suggest, reduced import prices from China appear to be the channel through which aggregate domestic prices in the G3 remain depressed. This paper particularly investigates the role of China's exchange rate regime among multilateral tradings. Findings highlight that China's multilateral trading strategy with G3 is beneficial for each participating member. In a coalition game, if US will purchase the products at the lowest bidding price, Euro zone and Japan are priced out of the market after bidding up the price to the lowest one. Moreover, if China follows an assignment game, then the multilateral trading is balanced. This is coincide with previous results that exchange rate volatility does have more influential impact on the import price volatilities of G3 since 2005 (Granville et al., 2011).

Anlyses in this paper also suggest that China's exchange rate policy is indeed a major role for balancing the trading between China and G3. Future work may test the empirical data for practical results.

\section{References}

[1] T. Cargill and E. Parker, "Price deflation, money demand, and monetary policy discontinuity: a comparative view of Japan, China, and the United States," North American Journal of Economics and Finance, pp. 125-147, 2004.

[2] B. Granville, S. Mallick and N. Zeng, "Chinese Exchange Rate and Price Effects on G3 Import Prices," Journal of Asian Economics, pp. 427-440, 2011.

[3] J. Frankel, "On the Yuan: The Choice between Adjustment under a Fixed Exchange Rate and Adjustment under a Flexible Rate," CESifo Economic Studies, pp. 246-275, 2006.

[4] L. Shapley and M. Shubik, "Competitive Equilibrium and Game Theory Solutions: Part I. The Core and Value," Cowles Foundation Discussion Papers 316, Cowles Foundation for Research in Economics, Yale University, 1971.

[5] Z. Zhang, "Exchange Rate Reform in China: An Experiment in the Real Targets Approach," The World Economy, pp. 1057-1081, 2000. 